Research Article

\title{
Comparative study of curcumin and curcumin formulated in a solid dispersion: Evaluation of their antigenotoxic effects
}

Leonardo Meneghin Mendonça $^{1,2}$, Carla da Silva Machado ${ }^{1,3}$, Cristiane Cardoso Correia Teixeira ${ }^{4}$, Luis Alexandre Pedro de Freitas ${ }^{4}$, Maria Lourdes Pires Bianchi ${ }^{1}$ and Lusânia Maria Greggi Antunes ${ }^{1}$

${ }^{1}$ Departamento de Análises Clínicas, Toxicológicas e Bromatológicas, Faculdade de Ciências

Farmacêuticas de Ribeirão Preto, Universidade de São Paulo, Ribeirão Preto, SP, Brazil.

${ }^{2}$ Departamento Farmacêutico, Universidade Federal de Juiz de Fora, Campus Governador Valadares, Governador Valadares, $M G$, Brazil.

${ }^{3}$ Departamento de Genética, Faculdade de Medicina de Ribeirão Preto, Universidade de São Paulo, Ribeirão Preto, SP, Brazil.

${ }^{4}$ Departamento de Ciências Farmacêuticas, Faculdade de Ciências Farmacêuticas de Ribeirão Preto, Universidade de São Paulo, Ribeirão Preto, SP, Brazil.

\begin{abstract}
Curcumin (CMN) is the principal active component derived from the rhizome of Curcuma longa (Curcuma longa L.). It is a liposoluble polyphenolic compound that possesses great therapeutic potential. Its clinical application is, however, limited by the low concentrations detected following oral administration. One key strategy for improving the solubility and bioavailability of poorly water-soluble drugs is solid dispersion, though it is not known whether this technique might influence the pharmacological effects of CMN. Thus, in this study, we aimed to evaluate the antioxidant and antigenotoxic effects of CMN formulated in a solid dispersion (CMN SD) compared to unmodified CMN delivered to Wistar rats. Cisplatin (CDDP) was used as the damage-inducing agent in these evaluations. The comet assay results showed that CMN SD was not able to reduce the formation of CDDP-DNA crosslinks, but it decreased the formation of micronuclei induced by CDDP and attenuated CDDP-induced oxidative stress. Furthermore, at a dose of $50 \mathrm{mg} / \mathrm{kg}$ b.w. both CMN SD and unmodified CMN increased the expression of Tp53 mRNA. Our results showed that CMN SD did not alter the antigenotoxic effects observed for unmodified CMN and showed effects similar to those of unmodified CMN for all of the parameters evaluated. In conclusion, CMN SD maintained the protective effects of unmodified CMN with the advantage of being chemically water soluble, with maximization of absorption in the gastrointestinal tract. Thus, the optimization of the physical and chemical properties of CMN SD may increase the potential for the therapeutic use of curcumin.
\end{abstract}

Keywords: Curcuma longa, antigenotoxicity, micronucleus test, DNA damage, comet assay.

Received: February 10, 2015; Accepted: May 28, 2015.

\section{Introduction}

Curcumin (1,7-bis[4-hydroxy 3-methoxy phenyl]1,6-heptadiene-3,5-dione, CMN) is the principal active component derived from the rhizome of Curcuma longa (Curcuma longa L.), which is commonly used in Ayurvedic and Chinese medicine, and serves in numerous other countries as a coloring agent or spice in many food preparations (Goel et al., 2008). CMN is a liposoluble polyphenolic compound, structurally consisting of two ring methoxyphenols attached to a $\beta$-diketone structure. The phenolic

Send correspondence to Lusânia Maria Greggi Antunes. Departamento de Análises Clínicas, Toxicológicas e Bromatológicas, Faculdade de Ciências Farmacêuticas de Ribeirão Preto, Universidade de São Paulo, Avenida do Café s/n, 14040-903 Ribeirão Preto, SP, Brazil. E-mail: lusania@ fcfrp.usp.br. groups and $\beta$-diketone are structures that are characteristic of antioxidant compounds and are critical for the antioxidant action of CMN (Singh et al., 2011).

CMN possesses an antioxidant capacity similar to that of potent antioxidants, such as the vitamin $\mathrm{E}$ analog trolox (Somparn et al., 2007). Studies have suggested that CMN inhibits lipid peroxidation in different tissues (Sreejayan and Rao, 1994), acts as an effective scavenger of intracellular reactive oxygen species (ROS) (Barzegar and Moosavi-Movahedi, 2011), and regulates intracellular levels of antioxidant enzymes (Naiket al., 2004). In addition to its recognized antioxidant activity, CMN possesses other pharmacological activities, including anti-inflammatory, anticancer and antidepressant properties (Aggarwal et al., 2013; Esatbeyoglu et al., 2015), and has been described as 
an antigenotoxic and antitumoral agent (Mendonça et al., 2009).

CMN also exhibits antigenotoxic effects in in vivo and in vitro models via reducing the chromosomal damage induced by physical and chemical agents (Antunes et al., 1999; Mendonça et al., 2009). The antioxidant and freeradical scavenging properties of $\mathrm{CMN}$ are considered important factors in its role in maintaining genomic stability, as oxidative stress can modify nitrogenous bases and result in DNA strand breaks (Premkumar et al., 2004).

Other biological effects of CMN include induction of cell cycle arrest, inhibition of cell proliferation, induction of apoptosis and modulation of gene expression (Zhou et al., 2011). In addition to acting at different levels of regulation of the process of cell growth and apoptosis, CMN operates in the initial processes of carcinogenesis by controlling chromosomal alterations and DNA damage (Duvoix et al., 2005).

Although CMN exhibits great therapeutic potential, its clinical application is frequently limited by the low blood concentrations obtained following oral administration. The low oral bioavailability of CMN was first demonstrated by Wahlstrom and Blennow (1978) and was attributed to poor absorption in the gastrointestinal tract, rapid metabolism, and rapid systemic elimination. Thus, studies have been performed with the aim of increasing the bioavailability of CMN. These involved synthesized analogues, combined use with CMN metabolism inhibitors (such as piperin) or newly developed formulations, such as nanoparticles, micelles, phospholipid complexes, and solid dispersions (Aggarwal and Harikumar, 2009).

Solid dispersion of drugs is an important strategy for improving the solubility of poorly water-soluble compounds, which often display low oral bioavailability, as is the case with CMN (Seo et al., 2012). This technology mixes one or more pharmacologically active compounds on a carrier, with the goal of altering their physicochemical properties, such as their stability, solubility and dissolution rate, which may result in greater bioavailability (Vasconcelos et al., 2007).

The evaluation of early genotoxicity is an essential part of the regulatory requirement and welfare considerations. In this study, we performed an in vivo comparative analysis between CMN formulated in a ternary solid dispersion (SD) composed of curcumin/gelucire ${ }^{\mathbb{R}} 50$ 13/aerosil ${ }^{\circledR}$ (CMN SD) and unmodified CMN to assess whether CMN SD can induce chromosomal damage or interfere with the recognized antioxidant and antigenotoxic properties of unmodified CMN. For this purpose, we measured genomic damage by means of comet assay in kidney and peripheral blood cells, as well as the micronucleus test in bone marrow from rats. We also evaluated oxidative stress via the analyses of reduced glutathione (GSH) and thiobarbituric-acid-reactive substances (TBARS) and examined the expression of Tp 53 mRNA in the kidney tissue.

\section{Materials and Methods}

\section{Chemicals}

CMN for CMN SD formulation was purchased from Asian Herbex Ltd (Hyderabad, India), gelucire ${ }^{\circledR}$ 50/13 was gently donated by Gattefosse Corp (Saint-Priest, France) and aerosil ${ }^{\circledR}$ obtained from EvonikInd AG (Germany). Unmodified CMN (CAS 458-37-7) was purchased from Sigma-Aldrich (St. Louis, MO, USA). The mixture of gelucire $^{\circledR} 50-13$ /aerosil ${ }^{\circledR}$ (GLA), which were components used in the preparation of CMN SD, was employed as a control in these experiments at a concentration equivalent to the highest applied dose of CMN SD.

Cisplatin (cDDP), which was used as a damageinducing agent due to its recognized genotoxic and nephrotoxic effects (Antunes et al., 2001), was purchased from Quiral Química do Brasil (Platinil ${ }^{\circledR}$, Juiz de Fora, Brazil). Trypan Blue (CAS 72-57-1), ethylenediaminetetraacetic acid (EDTA, CAS 60-00-4), Triton X-100 (CAS 900293-1) and Tris (CAS 77-86-1) were obtained from SigmaAldrich (St. Louis, MO, USA). Low melting point agarose (CAS: 9012-36-6) and normal melting point agarose (CAS: 9012-36-6) were purchased from Invitrogen (California, CA, USA). Dimethylsulfoxide was obtained from Merck (Darmstadt, Hessen, Germany). Other reagents were of analytical grade and of the purest quality available.

\section{Preparation of the solid dispersion}

CMN SD was prepared by the spray drying method. The carrier, Gelucire ${ }^{\circledR}$ 50/13 (Gatefosse, France), was melted in a water bath, and a solution of CMN in $50 \%$ ethanol was added (GLC: CUR, 1:1). This suspension containing equal parts of CMN and carrier was homogenised with a high shear mixer at 18,000 rpm and Aerosil (EvonikInd AG, Germany) was slowly added until 20\% (w/w). Further homogenisation using a high shear mixer $(14,000 \mathrm{rpm})$ was performed for $7 \mathrm{~min}$. The suspension obtained by this procedure was dried in a lab-scale spray dryer model MSD 0.5 (Labmaq Ltd., Ribeirão Preto, Brazil) using the following set conditions: suspension feed rate of $5 \mathrm{~mL} / \mathrm{min}$, atomisation air pressure of $4 \mathrm{kgf} / \mathrm{cm}^{2}$, drying air rate of $1.5 \mathrm{~m}^{3} / \mathrm{min}$, air outlet temperature of $40{ }^{\circ} \mathrm{C}$ and a suspension solids content of $7.5 \%(\mathrm{w} / \mathrm{w})$.

\section{Characterisation and stability of CMN SD}

The CMN SD microparticles were characterised by particle size, water activity, CMN content and solubility. Additionally, CMN SD physical-chemical properties were characterised by scanning electron microscopy (SEM), differential scanning calorimetry (DSC), thermogravimetry (TGA), infrared spectroscopy (FTIR) and X-ray powder diffraction (XRPD). Stability was assessed by DSC, TG, XRPD and FTIR after 3 and 6 months for samples kept at room temperature $\left(25^{\circ} \mathrm{C}\right)$ in triplicate. The stability was also evaluated by observing the solubility of samples after 
3, 6 and 9 months of storage at room temperature. The CMN SD microparticles resulted in a mean diameter of $550 \mathrm{~mm}$, and CMN content of $338.4 \mathrm{mg} / \mathrm{g}$. The thermal analysis by DSC and TGA showed no interaction among the components of CMN SD and this result was confirmed by the observations from FTIR and XRPD. The same was observed for these solid state characteristics after 3, 6 and 9 months, demonstrating an excellent stability of the microparticles. CMN solubility in its CMN SD form was determined to be $2.7 \mu \mathrm{g} / \mathrm{mL}$. Studies suggested that CMN SD is approximately 6.75 fold more water-soluble in comparison to unmodified CMN (Yallapu et al., 2012). The in vitro dissolution profiles of CMN-SD in phosphate buffer $\mathrm{pH} 7.4$ revealed that the release was $80 \%$ in only $10 \mathrm{~min}$.

\section{Animals}

Male Wistar albino rats, at 5-6 weeks of age and weighing approximately $160 \mathrm{~g}$ were obtained from the Animal Facility of the Ribeirão Preto Campus of the University of São Paulo. The animals were divided into 12 groups of six for each treatment. The experimental protocols applied in this study were approved by the Local Ethics Committee for Animal Use (CEUA) of Ribeirão Preto, Brazil, Register No.08.1.1417.53.2.

The rats were maintained in polypropylene cages with steel wire tops (three per cage), and the environmental controls were set to maintain conditions of $22 \pm 2{ }^{\circ} \mathrm{C}$ and $55 \pm 10 \%$ relative humidity under a 12 -h light-dark cycle. Fresh water and food were provided ad libitum. This study complied with national and international laws, and it was conducted in accordance with the conditions for animal care recommended by the Canadian Council on Animal Care (Olfert and McWilliam, 1993).

\section{Experimental design}

To determine whether the well-established protective effect of unmodified CMN demonstrated in other studies (Antunes et al., 1999) was also observed for CMN SD, treatments were performed with CMN SD (at 5, 25 and $50 \mathrm{mg} / \mathrm{kg}$ b.w.), unmodified CMN at $50 \mathrm{mg} / \mathrm{kg}$ b.w., saline solution or GLA. These were administered via gavage at $72 \mathrm{~h}, 48 \mathrm{~h}, 24 \mathrm{~h}$ or $30 \mathrm{~min}$ before the intraperitoneal administration of saline solution or the antitumoral agent cDDP, which was used as a damage-inducing agent.

The body weights of the rats were recorded daily. At $24 \mathrm{~h}$ after cDDP administration $\left(5^{\text {th }}\right.$ day), the animals were euthanized for sample collection. The dose of unmodified CMN applied in this study was defined from previously published studies in rodents (Ganta et al., 2010; Yu et al., 2011) and due the absence of toxic effects at macroscopic levels; and the dose of cDDP (6 mg/kg b.w.) was selected based on other studies that have shown that this dose induces chromosomal damage in rodents (Serpeloni et al., 2013). Adequate mass/mass relationship of CMN in unmodified CMN and CMN SD preparations were taken into consideration to obtain the doses used in the experiments. The same animals were used in genotoxicity assays (micronucleus test and comet assay) and biochemical tests (GSH and TBARS), as well as for the expression analysis of the Tp53 gene.

\section{Alkaline comet assay}

The alkaline version of the comet assay was performed according to protocols proposed by Singh et al. (1988) and Tice et al. (2000), with minor modifications (the slides were stained with GelRed, 1:10,000, Biotium-USA). To check for possible cytotoxic effects of the treatments, cell viability was determined via the Trypan blue dye exclusion method. Samples of peripheral blood and kidney cell suspensions ( $0.2 \mathrm{~g}$ of kidney tissue sliced into fragments in a Petri dish containing $2 \mathrm{~mL}$ of chilled Hank's solution) were mixed with $0.5 \%$ low melting point agarose dissolved in phosphate buffered saline and spread on microscope slides precoated with $1.5 \%$ normal melting agarose. The slides were immersed in freshly prepared lysis solution consisting of $2.5 \mathrm{M} \mathrm{NaCl}, 100 \mathrm{mM}$ EDTA, $1 \%$ Triton $\mathrm{X}-100$, and $10 \mathrm{mMTris}(\mathrm{pH} \mathrm{10})$ for at least $24 \mathrm{~h}$ at $4{ }^{\circ} \mathrm{C}$. Following lysis, the slides were placed in a horizontal electrophoresis unit containing $300 \mathrm{mM} \mathrm{NaOH}$ and $1 \mathrm{mM}$ EDTA $(\mathrm{pH}>13)$ for $20 \mathrm{~min}$ at an electric field strength of $0.78 \mathrm{~V} / \mathrm{cm}(25 \mathrm{~V}$ and $300 \mathrm{~mA})$. The slides were neutralized and stained with Gel Red (1:10,000). A total of 100 nucleoids per animal (two slides of 50 nucleoids each) were analysed at a 400x magnification using a fluorescence microscope (Axiostar, Zeiss, Germany) equipped with a 515-560 nm excitation filter, a $590 \mathrm{~nm}$ barrier filter and an integrated digital camera. Tail intensity ( $\%$ tail DNA) was evaluated using the Comet Assay IV software (Perceptive Instruments, Suffolk, UK).

\section{Micronucleus test}

The micronucleus test was performed according to the protocol described by Schmid (1975). Bone marrow cells were harvested from rat femurs, mixed with fetal bovine serum, homogenized and centrifuged, and the pellet was resuspended for slide preparations. The slides were then fixed, stained with Giemsa solution and coded. Three slides were produced for each animal. Coded slides were scored under $1000 \mathrm{X}$ magnification using a light microscope (Zeiss). For each of the six animals per group, 2000 polychromatic erythrocytes (PCEs) were scored, and the number of micronucleated PCE (MNPCE) was recorded. The percentage of PCE among 500 erythrocytes was calculated as a measure of erythroblast proliferation $[\mathrm{PCE} /(\mathrm{PCE}$ $+\mathrm{NCE})]$.

\section{TBARS and GSH levels in the kidney}

TBARS measurements in kidney tissue were performed according to Buege and Aust (1978). A $0.5 \mathrm{~mL}$ aliquot of the homogenate was added to $1 \mathrm{~mL}$ of thiobar- 
bituric acid solution (containing 15\% trichloroacetic acid and $0.25 \mathrm{M} \mathrm{HCl}$ ) to a final concentration of $26 \mathrm{nM}$. This mixture was warmed in a water bath for 15 min and centrifuged for $20 \mathrm{~min}$ at $180 \mathrm{xg}$. The absorbance of the supernatant was determined at $535 \mathrm{~nm}$ (UV-VisB582 Micronal spectrophotometer), and the results were expressed as nmol TBARS/mg protein. The breakdown of the product 1,1,3,3-tetraetoxypropane was used as the standard reaction.

GSH concentrations in kidney tissue were determined according to method described by Sedlak and Lindsay (1968). The homogenate samples were diluted in water (1:4), precipitated with $50 \%$ trichloroacetic acid and then centrifuged at $150 \mathrm{x} \mathrm{g}$ for $10 \mathrm{~min}$. A $2.0 \mathrm{~mL}$ volume of Tris-EDTA buffer $(0.2 \mathrm{M}, \mathrm{pH} 8.9)$ and $0.1 \mathrm{~mL}$ of 5,5 "-dithio-bis-2-nitrobenzoic acid (DTNB) in $0.01 \mathrm{M}$ methanol were added to a $0.5 \mathrm{~mL}$ aliquot of the supernatant. The samples were maintained at room temperature for $15 \mathrm{~min}$ and then read at $412 \mathrm{~nm}$ (RayLeigh UV-1601 spectrophotometer). Standard curves were prepared using $\alpha$-cysteine, and results were expressed as $\mathrm{nmol} \mathrm{GSH} / \mathrm{g}$ protein.

The quantification of total proteins was done at $650 \mathrm{~nm}$ (RayLeigh UV-1601 spectrophotometer) using Lowry's method (Hartree, 1972).

\section{Quantification of Tp53 mRNA}

Total RNA was extracted from kidney tissue using the SV Total Isolation System kit (Promega, Madison, WI, USA), according the manufacturer's instructions. The integrity of the extracted RNA was assessed via gel electrophoresis in $1.0 \%$ agarose, and the purity was measured based on the ratios of the spectrophotometric optical density measurements taken at $260 \mathrm{~nm} / 280 \mathrm{~nm}$ and $260 \mathrm{~nm} / 230 \mathrm{~nm}$. The extracted RNA was converted to cDNA using the SuperScriptTM III kit (Invitrogen, Carlsbad, CA, USA), and RT-qPCR was performed in a CFX96 Real-Time PCR Detection System (Bio-Rad, CA, USA) using the Bio-Rad Real-Time PCR system with ABsoluteTM QPCR SYBR1 Green Mix (Invitrogen, Carlsbad, CA, USA), where fluorescence detection was performed following each annealing/extension cycle.

The following reference genes were tested for suitability: b-actin (b-actin-forward: TCCTGTGGCATCCAT GAACT; b-actin reverse: CCAGGGCAGTAATCTCTTT CTTCTG), GAPDH (GAPDH-forward: GGCATCGTGG AAGGGCTCAT; GAPDH-reverse: GCCATCACGCC ACAGCTTTC) and HKI (HKI-forward: GCGAGGGGA CTATGATGCT; HKI-reverse CGCAGTTCCTCCATGT AGC). Based on stability, we selected b-actin as the endogenous control gene for RT-qPCR. Gene-specific primers for $T p 53$ (Tp53-forward: CATCATCACGCTGGAAGAC TC; Tp53-reverse: TTCAGCTCTCGGAACATCTC) and b-actin (Nair et al., 2004) were synthesized by SigmaAldrich (St. Louis, MO, USA).
RT-qPCR efficiencies for $T p 53$ and b-actin were satisfactory, and the relative expression of $T p 53$ mRNA was normalized to the amount of b-actin using the method of relative $2^{-\Delta \Delta \mathrm{Ct}}$ quantification described by Livak and Schmittgen (2001).

\section{Data analysis}

Statistical analysis was performed using GraphPad Prism 5.0 software. The results are expressed as the means \pm standard deviation. Analysis of variance (ANOVA) followed by Tukey's post hoc tests was employed to calculate statistically significant differences (at $p<0.05$ ) in the results obtained for the treatment $v s$. saline solution group.

\section{Results}

\section{Variation in body mass and the relative mass of the kidney}

Body weights of the animals were recorded daily (Table 1). Prior to the intraperitoneal injection cDDP, no variation in body weight gain was observed in any group. The experimental groups that received cDDP intraperitoneally showed reduced body weight gain compared to the saline control group. Combined application of CMN SD or unmodified CMN with cDDP did not alter the reduction of body weight gain triggered by cDDP. We measured the kidney weight/body weight ratio as a toxicity parameter. No difference was observed between the treatment groups and the saline solution group for this parameter (Table 1).

\section{CMN SD reduces chromosomal damage induced by CDDP}

The capacity of CMN SD or unmodified CMN to reduce DNA and chromosomal damage induced by cDDP was evaluated using the comet and micronucleus assays, respectively.

Cell viability observed in the kidney and peripheral blood was greater than $70 \%$ in all of the analysed groups, in accordance with recommendations for performing a comet assay analysis (Azqueta and Collins, 2013), as shown in Table 2. In the comet assay, the extent of DNA damage was assessed based on the tail intensity parameter (\% tail DNA).

No genotoxic effects of CMN SD, unmodified CMN or GLA were observed in kidney or peripheral blood cells (Table 2). The results regarding \% tail DNA observed in the animals treated with cDDP revealed a significant decrease in DNA migration compared to the saline solution group in renal tissue, but not in peripheral blood (Table 2). The results for the cDDP group indicated the formation of crosslinks with DNA. Treatment with CMN SD or unmodified CMN in association with cDDP did not induce significant alterations compared to the cDDP-only group in the comet assay.

The PCE/(NCE + PCE) ratio revealed no significant differences between the treatment groups and saline solu- 
Table 1 - Evaluation of the variation of mass gain in rats after subacute treatment with CMN SD, unmodified CMN, cDDP and their associations.

\begin{tabular}{lccc}
\hline Treatments & Body weight $(\mathrm{g})^{\mathrm{a}}$ mean \pm standard deviation & Body weight $(\mathrm{g})^{\mathrm{b}}$ mean \pm standard deviation & Kidney/body weight $(\%)$ \\
\hline Saline solution & $29.7 \pm 6.4$ & $11.3 \pm 2.1$ & $0.98 \pm 0.03$ \\
GLA & $31.3 \pm 5.6$ & $9.3 \pm 4.7$ & $1.01 \pm 0.04$ \\
CMN SD 5 & $31.2 \pm 6.6$ & $11.0 \pm 2.8$ & $0.93 \pm 0.05$ \\
CMN SD 25 & $28.0 \pm 4.6$ & $9.2 \pm 7.3$ & $0.93 \pm 0.09$ \\
CMN SD 50 & $25.5 \pm 8.2$ & $8.5 \pm 1.0$ & $1.00 \pm 0.11$ \\
CMN 50 & $31.7 \pm 6.6$ & $8.2 \pm 2.4$ & $0.96 \pm 0.05$ \\
cDDP & $34.0 \pm 4.3$ & $0.6 \pm 3.9^{*}$ & $1.03 \pm 0.04$ \\
GLA + cDDP & $27.5 \pm 6.1$ & $0.8 \pm 2.2^{*}$ & $1.02 \pm 0.11$ \\
CMN SD 5 + cDDP & $29.7 \pm 3.8$ & $1.8 \pm 1.5^{*}$ & $0.97 \pm 0.05$ \\
CMN SD 25 + cDDP & $26.7 \pm 5.8$ & $2.3 \pm 4.8^{*}$ & $0.97 \pm 0.06$ \\
CMN SD 50 + cDDP & $23.0 \pm 5.3$ & $0.2 \pm 4.5^{*}$ & $1.00 \pm 0.09$ \\
CMN 50 + cDDP & $31.8 \pm 4.7$ & $0.1 \pm 2.5^{*}$ & $0.90 \pm 0.06$ \\
\hline
\end{tabular}

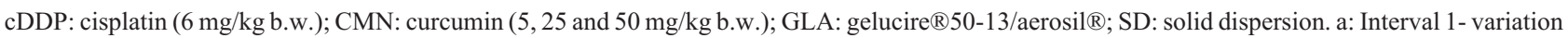
in body mass, in grams $(\mathrm{g})$, between days 1 and 4 of the experimental period. b: Interval 2 -variation in body mass, in grams (g), between day 4 and 5 of the experimental period. The results represent the mean \pm standard deviation for each group (six animals/group). *Significantly different from saline solution group, assessed by ANOVA and Tukey's post hoc test $(\mathrm{p}<0.05)$.

Table 2 - Tail Intensity (\% tail DNA) and cell viability (expressed as \% in relation to saline solution group) in cells of kidney and peripheral blood after subacute treatment with CMN SD, unmodified CMN, cDDP and their associations, analyzed in the comet assay.

\begin{tabular}{|c|c|c|c|c|}
\hline \multirow[t]{2}{*}{ Treatments } & \multicolumn{2}{|c|}{$\%$ tail DNA } & \multicolumn{2}{|c|}{ Cell viability (\%) } \\
\hline & Kidney & Peripheral blood & Kidney & Peripheral blood \\
\hline Saline solution & $7.4 \pm 4.0$ & $4.4 \pm 2.1$ & $100.0 \pm 0.0$ & $100.0 \pm 0.0$ \\
\hline GLA & $8.3 \pm 2.9$ & $2.6 \pm 0.7$ & $88.5 \pm 1.9$ & $98.8 \pm 0.7$ \\
\hline CMN SD5 & $9.4 \pm 2.8$ & $4.7 \pm 1.6$ & $91.2 \pm 2.4$ & $99.2 \pm 0.7$ \\
\hline CMN SD 25 & $6.7 \pm 1.7$ & $4.8 \pm 0.6$ & $88.0 \pm 2.6$ & $98.7 \pm 0.5$ \\
\hline CMN SD 50 & $7.5 \pm 3.0$ & $2.1 \pm 1.1$ & $88.5 \pm 3.3$ & $99.0 \pm 0.6$ \\
\hline CMN 50 & $5.5 \pm 2.8$ & $3.2 \pm 0.9$ & $89.0 \pm 2.3$ & $98.7 \pm 0.5$ \\
\hline $\mathrm{cDDP}$ & $3.4 \pm 1.1^{*}$ & $2.5 \pm 0.4$ & $89.7 \pm 1.7$ & $99.2 \pm 0.7$ \\
\hline $\mathrm{GLA}+\mathrm{cDDP}$ & $3.8 \pm 0.7^{*}$ & $2.2 \pm 0.8$ & $86.5 \pm 3.1$ & $98.8 \pm 0.7$ \\
\hline CMN SD $5+$ cDDP & $5.0 \pm 1.1$ & $3.0 \pm 1.7$ & $90.5 \pm 2.5$ & $99.8 \pm 0.7$ \\
\hline CMN SD $25+$ cDDP & $6.4 \pm 1.1$ & $4.4 \pm 1.2$ & $87.3 \pm 3.6$ & $98.5 \pm 1.2$ \\
\hline CMN SD $50+$ cDDP & $5.7 \pm 1.1$ & $3.3 \pm 1.5$ & $85.5 \pm 4.4$ & $98.5 \pm 1.4$ \\
\hline CMN $50+$ cDDP & $4.0 \pm 0.8$ & $2.1 \pm 0.6$ & $88.5 \pm 2.2$ & $99.2 \pm 0.7$ \\
\hline
\end{tabular}

Saline solution or CDDP was administered intraperitoneally $30 \mathrm{~min}$ after the last gavage of CMN SD or unmodified CMN. \%: percentage; cDDP: cisplatin

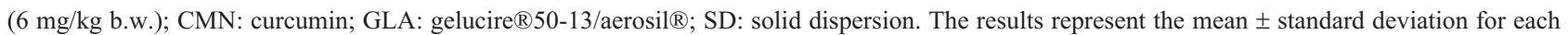
group (six animals/group). *Significantly different from saline solution group, assessed by ANOVA and Tukey's post hoc test $(\mathrm{p}<0.05)$.

tion group (Table 3), indicating that none of the treatments altered the rate of cell division in bone marrow. Table 3 shows the effect of CMN SD or unmodified CMN, either combined with cDDP or not, on the formation of micronuclei. CMN SD, unmodified CMN and the GLA mixture did not induce micronucleus formation. In contrast, cDDP treatment significantly increased the frequency of MNPCE compared to the saline solution group. CMN SD (at 5, 25 and $50 \mathrm{mg} / \mathrm{kg}$ b.w.) and unmodified CMN (50 mg/kg b.w.) significantly reduced the formation of cDDP-induced micronuclei $(p<0.05)$. This effect occurred to a similar extent under treatment with CMN SD and CMN at a dose of $50 \mathrm{mg} / \mathrm{mL}$.

\section{CMN SD attenuates CDDP-induced oxidative stress}

Oxidative stress was evaluated by measuring the concentrations of TBARS and GSH in renal tissue 24 hours after cDDP administration. When administered alone, CMN 
Table 3 - Frequency of micronucleated polychromatic erythrocytes (MNPCE) and the percentage (\%) of PCE/(PCE + NCE) in 500 erythrocytes in the bone morrow of Wistar rats treated with CMN SD, unmodified CMN, cDDP or their associations, analyzed in the micronucleus test.

\begin{tabular}{lcc}
\hline \multirow{2}{*}{ Treatment } & \multicolumn{2}{c}{ Bone marrow erythrocytes } \\
\cline { 2 - 3 } & MNPCEs/1000 PCEs & $\begin{array}{c}\text { PCE/(PCE + NCE) } \\
\text { ratio (\%) }\end{array}$ \\
\hline Saline solution & $1.25 \pm 0.78$ & $52.6 \pm 4.6$ \\
GLA & $1.92 \pm 1.1$ & $54.7 \pm 6.5$ \\
CMN SD 5 & $2.25 \pm 1.13$ & $59.3 \pm 6.2$ \\
CMN SD 25 & $1.5 \pm 0.82$ & $53.4 \pm 10.4$ \\
CMN SD 50 & $2.42 \pm 1.09$ & $43.2 \pm 6.0$ \\
CMN 50 & $1.91 \pm 1.27$ & $55.7 \pm 8.8$ \\
cDDP & $13.25 \pm 3.51^{*}$ & $49.9 \pm 5.6$ \\
GLA + cDDP & $12.75 \pm 3.32^{*}$ & $44.8 \pm 4.9$ \\
CMN SD 5 + cDDP & $6.88 \pm 1.77^{* \#}$ & $51.8 \pm 5.9$ \\
CMN SD 25 + cDDP & $5.33 \pm 2.98^{* \#}$ & $53.9 \pm 8.3$ \\
CMN SD 50 + cDDP & $6.42 \pm 3.12^{* \#}$ & $51.1 \pm 3.0$ \\
CMN 50 + cDDP & $7.08 \pm 3.04^{* \#}$ & $51.0 \pm 7.5$ \\
\hline
\end{tabular}

Saline solution or cDDP was administered intraperitoneally 30 min after the last gavage of CMN SD or unmodified CMN. cDDP: cisplatin (6 mg/kg b.w.); CMN: curcumin (5, 25 and $50 \mathrm{mg} / \mathrm{kg}$ b.w.); GLA:

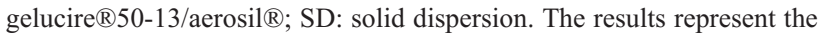
mean \pm standard deviation for each group (six animals/group).*Significantly different from saline solution group. \#Significantly different from cDDP group, assessed by ANOVA and Tukey's post hoc test $(\mathrm{p}<0.05)$.

SD and unmodified CMN did not alter the GSH and TBARS concentrations detected in renal tissue (Table 4). cDDP significantly increased TBARS levels compared to the saline solution group but did not alter GSH levels. CMN SD or unmodified CMN, administered together with cDDP, was able to maintain the TBARS levels observed in the saline solution group $(p>0.05)$ (Table 4$)$. There was no significant difference between the groups treated with GLA together with cDDP vs. cDDP alone.

\section{Tp53 mRNA levels are affected by CMN SD}

Figure 1 shows the effects of CMN SD $(50 \mathrm{mg} / \mathrm{kg}$ b.w.) and unmodified CMN (50 mg/kg b.w.), either alone or in association with cDDP $(6 \mathrm{mg} / \mathrm{kg}$ b.w.), on the $T p 53$ mRNA levels in kidney tissue. The results showed that CMN SD, unmodified CMN and cDDP did not alter Tp53 gene expression compared to the saline solution group. However, when either CMN SD or unmodified CMN was administered together with cDDP, $T p 53$ expression was up-regulated compared to saline solution group. There was no difference in the levels of Tp53 mRNA in kidney cells when comparing the CMN SD and unmodified CMN groups.
Table 4 - Evaluation of reduced glutathione (GSH) and thiobarbituricacid-reactive substances (TBARS) in the kidney of Wistar rats treated with CMN SD, unmodified CMN, cDDP or their associations.

\begin{tabular}{lcc}
\hline Treatments & $\begin{array}{c}\text { GSH (nmol/mg } \\
\text { protein) }\end{array}$ & $\begin{array}{c}\text { TBARS } \\
\text { (nmol/mg protein) }\end{array}$ \\
\hline Saline solution & $18.9 \pm 0.4$ & $0.249 \pm 0.011$ \\
GLA & $17.7 \pm 2.6$ & $0.226 \pm 0.023$ \\
CMN SD5 & $14.2 \pm 1.3$ & $0.237 \pm 0.018$ \\
CMN SD 25 & $15.3 \pm 1.1$ & $0.232 \pm 0.026$ \\
CMN SD 50 & $17.2 \pm 1.7$ & $0.247 \pm 0.018$ \\
CMN 50 & $14.4 \pm 1.2$ & $0.236 \pm 0.018$ \\
cDDP & $15.2 \pm 3.5$ & $0.302 \pm 0.026^{*}$ \\
GLA+ cDDP & $18.5 \pm 0.6$ & $0.286 \pm 0.014^{*}$ \\
CMN SD 5 + cDDP & $16.6 \pm 1.3$ & $0.215 \pm 0.009^{\#}$ \\
CMN SD 25 + cDDP & $14.0 \pm 1.7$ & $0.200 \pm 0.011^{\#}$ \\
CMN SD 50 + cDDP & $19.1 \pm 2.5$ & $0.218 \pm 0.018^{\#}$ \\
CMN 50 + cDDP & $17.0 \pm 1.4$ & $0.222 \pm 0.064^{\#}$ \\
\hline
\end{tabular}

Saline solution or cDDP was administered intraperitoneally 30 min after the last gavage of CMN SD or unmodified CMN. cDDP: cisplatin (6 mg/kg b.w.); CMN: curcumin (5, 25 and $50 \mathrm{mg} / \mathrm{kg}$ b.w.); GLA:

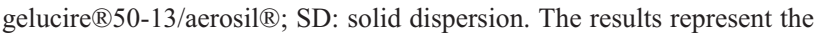
mean \pm standard deviation for each group (six animals/group). *Significantly different from saline solution and GLA groups. \#Significantly different from cDDP group, assessed by ANOVA and Tukey's post hoc test $(\mathrm{p}<0.05)$.

\section{Discussion}

With the objective of evaluating whether CMN SD could induce chromosomal damage or interfere with the recognized antioxidant and antigenotoxic properties of un-

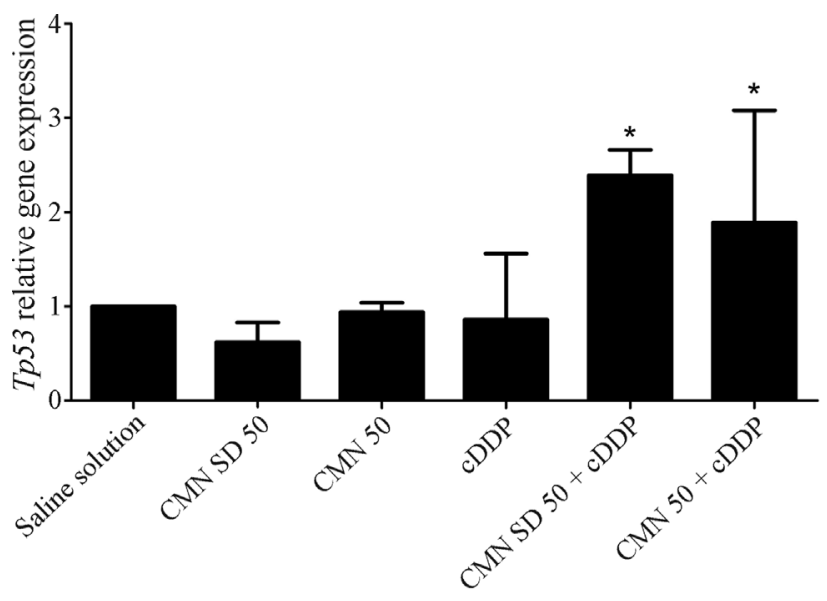

Figure 1 - Relative quantification of $T p 53$ mRNA in kidney cells following treatment with CMN SD (50 mg/kg b.w.), unmodified CMN (50 $\mathrm{mg} / \mathrm{kg}$ b.w.) and cDDP alone or in combination. The housekeeping gene b-actin was used for normalization of the samples. The results represent the mean \pm standard deviation for each group (six animals/group). *Statistically significantly different from the saline solution group, as assessed by ANOVA and Tukey's post hoc test $(\mathrm{p}<0.05)$. 
modified CMN, we performed an in vivo comparative analysis between CMN SD and unmodified CMN, by measuring DNA damage, evaluating oxidative stress and analysing Tp53 mRNA levels. Our results showed that CMN SD decreased chromosomal damage induced by cDDP, up-regulated $T p 53$ expression when administered together with cDDP, and attenuated CDDP-induced oxidative stress. There were no significant differences observed between the effects of CMN SD and unmodified CMN for any of the parameters evaluated in this study.

cDDP was used as the damage-inducing agent in this study due its genotoxic and nephrotoxic effects, and the kidney was evaluated as a target organ. The genotoxic mechanisms of cDDP involve chromosomal damage, as demonstrated by the induction of micronuclei (Gupta et al., 2011); the formation of cDDP-DNA crosslinks, as shown by the decrease in the percentage of DNA in the tail (Stang and Witte, 2009), and the regulation of Tp53 mRNA and p53 protein levels (Yuan et al., 2011). The in vivo mechanisms of cDDP nephrotoxicity are mainly related to the induction of oxidative stress: cDDP increases free radical production (Ognjanovic et al., 2012) and decreases antioxidant enzyme activity (Badary et al., 2005).

According to Wolfsegger et al. (2009), the changes in total mass of an animal and the relationship between organ weights and total mass of an animal can be used as an indication of the toxicity of a compound under evaluation. Animals treated with CMN SD and unmodified CMN showed no difference in total mass compared to the saline solution group. However, there was a significant reduction in body mass of the rats treated with cDDP $(6 \mathrm{mg} / \mathrm{kg}$ b.w.) compared to the saline solution group. Other studies in rodents have also shown a decrease in body mass following cDDP administration at the same dose as applied in this study (Zhang et al., 1999). This is most likely due to cytotoxic effects of cDDP.

Assessment of chromosomal damage was performed via the micronucleus test in erythrocytes from bone marrow, and DNA damage was evaluated using the comet assay in kidney and peripheral blood samples. These two tests are frequently employed to evaluate the genotoxic and mutagenic effects of physical or chemical agents, where by the comet assay can detect initial lesions in DNA, and the micronucleus assay can detect chromosomal breaks and losses (Bowen et al., 2011; Collins, 2015). DNA lesions detected by the comet assay can be single- and double-strand breaks, alkaline-labile sites and DNA-DNA and DNAprotein crosslinks. Single- or double-strand breaks and alkaline-labile sites are further identified in the comet assay as an increase in DNA migration, while DNA-DNA and DNA-protein crosslinks are detected as a decrease in DNA migration (Nesslany et al., 2007).

CMN SD did not induce DNA or chromosomal damage in any of the analysed tissues, suggesting that CMN SD did not induce genotoxicity in these. Regarding the anti- genotoxicity action of CMN SD, we saw that it reduced micronucleus formation in the bone marrow cells of rats exposed to cDDP, but did not reduce the formation of cDDPDNA crosslinks observed in kidney. The antigenotoxicity of CMN SD was similar to that of unmodified CMN in this study, a finding that is comparable to that reported in other studies involving CMN (Mendonça et al., 2009; Celik et al., 2013). These results furthermore suggest that the protective mechanism of CMN SD is not related to a reduction in the formation of cDDP-DNA crosslinks, since CMN SD did not interfere with the mechanism of cDDP genotoxicity. It seems, however, related with the reduction of cDDP-induced breaks and loss of chromosomes.

Various studies have demonstrated the relevance of oxidative stress in cDDP-induced cellular damage. Oxidative stress can cause DNA damage, resulting in strand breaks, alterations in gene expression, and mutations (Cooke et al., 2003). Some antioxidant agents may exert their protective effects by increasing the capacity of cellular antioxidant defense systems, or via the sequestration of reactive species (Costa et al., 2012), and the protective effects of CMN, as well as its antigenotoxicity activity are often related to its antioxidant properties.

In this study, the evaluated oxidative stress parameters were the GSH concentration and TBARS formation in renal tissue. It is generally accepted that the mechanism by which cDDP induces oxidative stress in renal tissue involves the induction of lipid peroxidation (Ognjanovic et al., 2012), and the antioxidant properties of CMN are related to its ability to modulate the concentrations of GSH and TBARS (Biswas et al., 2005; Kaur et al., 2006). Some findings suggest that $\mathrm{CMN}$ could be useful in reducing the nephrotoxicity of cDDP (Swamy et al., 2012), and our results showed that CMN SD, when administered together with cDDP, was able to maintain the TBARS levels observed in the saline solution group. These results suggest that CMN SD, processed via spray dry technology, can protect against cDDP-induced lipid peroxidation in the kidney and maintain TBARS at basal levels.

In addition, we assessed the expression of $T p 53$ in kidney cells because the involvement of $\mathrm{p} 53$ protein has been implicated in cDDP toxicity in normal cells, as observed in nephrotoxicity (Jiang and Dong, 2008). Like unmodified CMN, CMN SD increased the mRNA levels of $T p 53$ when administered together with cDDP in renal tissue, compared to the saline group; and they did not alter the Tp53 mRNA levels when compared to the cDDP group. In renal tubule cells, $\mathrm{p} 53$ proteins inhibitors are thought to interfere with the efficacy of cDDP (Jiang and Dong, 2008). While the results obtained in the present study suggest that CMN SD did not interfere with cDDP in $T p 53$ gene expression, it was not possible to rule out effects on $\mathrm{p} 53$ protein.

Recent studies have suggested an "integrated toxicology" strategy to define the pharmacological and biological potential of new compounds, and genotoxicity assays have 
been of great relevance for the development of new drugs (Hornberg et al., 2014). Our findings demonstrate that the technique of producing a solid dispersion containing CMN did not affect the antigenotoxic effects of this compound, and CMN SD showed effects similar to those of unmodified CMN for all of the evaluated parameters. In conclusion, CMN SD maintained the protective and antioxidant effects of unmodified CMN with the advantage of being chemically water soluble. Thus, the optimization of the physical and chemical properties of CMN SD may increase its potential for therapeutic use.

\section{Acknowledgments}

This research was supported by CAPES (Coordenação de Aperfeiçoamento de Pessoal de Ensino Superior), CNPq (Conselho Nacional de Desenvolvimento Científico e Tecnológico) and the São Paulo Research Foundation (FAPESP), grants \#2008/53947-7 and \#2008/10482-4. LMM was sponsored by a fellowship from the São Paulo Research Foundation FAPESP (grant \#2008/10482-4).

\section{References}

Aggarwal BB and Harikumar KB (2009) Potential therapeutic effects of curcumin, the anti-inflammatory agent, against neurodegenerative, cardiovascular, pulmonary, metabolic, autoimmune and neoplastic diseases. Int $\mathrm{J}$ Biochem Cell Biol 41:40-59.

Aggarwal BB, Yuan W, Li S and Gupta SC (2013) Curcumin-free turmeric exhibits anti-inflammatory and anticancer activities: Identification of novel components of turmeric. Mol Nutr Food Res 57:1529-1542.

Antunes LM, Araujo MC, Dias FL and Takahashi CS (1999) Modulatory effects of curcumin on the chromosomal damage induced by doxorubicin in Chinese hamster ovary cells. Teratog Carcinog Mutagen 19:1-8.

Antunes LM, Darin JD and Bianchi MdL (2001) Effects of the antioxidants curcumin or selenium on cisplatin-induced nephrotoxicity and lipid peroxidation in rats. Pharmacol Res 43:145-150.

Azqueta A and Collins AR (2013) The essential comet assay: A comprehensive guide to measuring DNA damage and repair. Arch Toxicol 87:949-968.

Badary OA, Abdel-Macsoud S, Ahmed WA and Owieda GH (2005) Naringenin attenuates cisplatin nephrotoxicity in rats. Life Sci 76:2125-2135.

Barzegar A and Moosavi-Movahedi AA (2011) Intracellular ROS protection efficiency and free radical-scavenging activity of curcumin. PLoS One 6:e26012.

Biswas SK, McClure D, Jimenez LA, Megson IL and Rahman I (2005) Curcumin induces glutathione biosynthesis and inhibits NF-kappaB activation and interleukin-8 release in alveolar epithelial cells: Mechanism of free radical scavenging activity. Antioxid Redox Signal 7:32-41.

Bowen DE, Witwell JH, Lillford L, Henderson D, Kidd D, Mc Garry S, Pearce G, Beevers C and Kirkland DJ (2011) Evaluation of a multi-endpoint assay in rats, combining the bone-marrow micronucleus test, the Comet assay and the flow-cytometric peripheral blood micronucleus test. Mutat Res 722:7-19.

Buege JA and Aust SD (1978) Microsomal lipid peroxidation. Methods Enzymol 52:302-310.

Celik A, Eke D, Ekinci SY and Yildirim S (2013) The protective role of curcumin on perfluorooctane sulfonate-induced genotoxicity: Single cell gel electrophoresis and micronucleus test. Food Chem Toxicol 53:249-255.

Collins AR (2015) The comet assay: A heavenly method! Mutagenesis 30:1-4.

Cooke MS, Evans MD, Dizdaroglu M and Lunec J (2003) Oxidative DNA damage: Mechanisms, mutation, and disease. FASEB J 17:1195-1214.

Costa LA, Badawi A and El-Sohemy A (2012) Nutrigenetics and modulation of oxidative stress. Ann Nutr Metab 60:27-36.

Duvoix A, Blasius R, Delhalle S, Schenekenburger M, Morceau F, Henry E, Dicato M and Diederich M (2005) Chemopreventive and therapeutic effects of curcumin. Cancer Lett 223:181-190

Esatbeyoglu T, Ulbrich K, Rehberg C, Rohn S and Rimbach G (2015) Thermal stability, antioxidant, and anti-inflammatory activity of curcumin and its degradation product 4-vinyl guaiacol. Food Funct 6:887-893.

Ganta S, Devalapally H and Amiji M (2010) Curcumin enhances oral bioavailability and anti-tumor therapeutic efficacy of paclitaxel upon administration in nanoemulsion formulation. J Pharm Sci 99:4630-4641.

Goel A, Kunnumakkara AB and Aggarwal BB (2008) Curcumin as "Curecumin": From kitchen to clinic. Biochem Pharmacol 75:787-809.

Gupta V, Agrawal RC and Trivedi P (2011) Reduction in cisplatin genotoxicity (micronucleus formation) in non target cells of mice by protransfersome gel formulation used for management of cutaneous squamous cell carcinoma. Acta Pharm 61:63-71.

Hartree EF (1972) Determination of protein: A modification of the Lowry method that gives a linear photometric response. Anal Biochem 48:422-427.

Hornberg JJ, Laursen M, Brenden N, Persson M, Thougaard AV, Toff DB and Mow T (2014) Exploratory toxicology as an integrated part of drug discovery. Part I: Why and how. Drug Discov Today 19:1131-1136.

Jiang M and Dong Z (2008) Regulation and pathological role of p53 in cisplatin nephrotoxicity. J Pharmacol Exp Ther 327:300-307.

Kaur G, Tirkey N, Bharrhan S, Chanana V, Rishi P and Chopra K (2006) Inhibition of oxidative stress and cytokine activity by curcumin in amelioration of endotoxin-induced experimental hepatoxicity in rodents. Clin Exp Immunol 145:313-321.

Livak KJ and Schmittgen TD (2001) Analysis of relative gene expression data using real-time quantitative PCR and the 2(-Delta Delta C(T)) method. Methods 25:402-408.

Mendonça LM, Dos Santos GC, Antonucci GA, Dos Santos AC, Bianchi ML and Antunes LM (2009) Evaluation of the cytotoxicity and genotoxicity of curcumin in PC12 cells. Mutat Res 675:29-34.

Naik RS, Mujumdar AM and Ghaskadbi S (2004) Protection of liver cells from ethanol cytotoxicity by curcumin in liver slice culture in vitro. J Ethnopharmacol 95:31-37. 
Nair VD, Yuen T, Olanow CW and Sealfon SC (2004) Early single cell bifurcation of pro- and antiapoptotic states during oxidative stress. J Biol Chem 279:27494-27501.

Nesslany F, Zennouche N, Simar-Meintieres S, Talahari I, NkiliMboui EN and Marzin D (2007) In vivo Comet assay on isolated kidney cells to distinguish genotoxic carcinogens from epigenetic carcinogens or cytotoxic compounds. Mutat Res 630:28-41.

Ognjanovic BI, Djordjevic NZ, Matic MM, Obradovic JM, Mladenovic JM, Stajin AS and Saicic ZS (2012) Lipid peroxidative damage on Cisplatin exposure and alterations in antioxidant defense system in rat kidneys: A possible protective effect of selenium. Int J Mol Sci 13:1790-1803.

Olfert ED and McWilliam AA (1993) Guide to the care and use of experimental animals. 2nd edition. Canadian Council on Animal Care, Ottawa, 211 p.

Premkumar K, Kavitha S, Santhiya ST, Ramesh AR and Suwanteerangkul J (2004) Interactive effects of saffron with garlic and curcumin against cyclophosphamide induced genotoxicity in mice. Asia Pac J Clin Nutr 13:292-294.

Schmid W (1975) The micronucleus test. Mutat Res 31:9-15.

Sedlak J and Lindsay RH (1968) Estimation of total, proteinbound, and nonprotein sulfhydryl groups in tissue with Ellman's reagent. Anal Biochem 25:192-205.

Seo SW, Han HK, Chun MK and Choi HK (2012) Preparation and pharmacokinetic evaluation of curcumin solid dispersion using Solutol(R) HS15 as a carrier. Int J Pharm 424:18-25.

Serpeloni JM, Batista BL, Angeli JP, Barcelos GR, Bianchi Mde L, Barbosa FJ and Antunes LM (2013) Antigenotoxic properties of chlorophyll b against cisplatin-induced DNA damage and its relationship with distribution of platinum and magnesium in vivo. J Toxicol Environ Health 76:345-353.

Singh NP, McCoy MT, Tice RR and Schneider EL (1988) A simple technique for quantitation of low levels of DNA damage in individual cells. Exp Cell Res 175:184-191.

Singh U, Barik A, Singh BG and Priyadarsini KI (2011) Reactions of reactive oxygen species (ROS) with curcumin analogues: Structure-activity relationship. Free Radic Res 45:317-325.

Somparn P, Phisalaphong C, Nakornchai S, Unchern S and Morales NP (2007) Comparative antioxidant activities of curcumin and its demethoxy and hydrogenated derivatives. Biol Pharm Bull 30:74-78.
Sreejayan and Rao MN (1994) Curcuminoids as potent inhibitors of lipid peroxidation. J Pharm Pharmacol 46:1013-1016.

Stang A and Witte I (2009) Performance of the comet assay in a high-throughput version. Mutat Res 675:5-10.

Swamy AV, Gulliaya S, Thippeswamy A, Koti BC and Manjula DV (2012) Cardioprotective effect of curcumin against doxorubicin-induced myocardial toxicity in albino rats. Indian J Pharmacol 44:73-77.

Tice RR, Agurell E, Anderson D, Burlinson B, Hartmann A, Kobayashi H, Miyamae Y, Rojas E, Ryu JC and Sasaki YF (2000) Single cell gel/comet assay: Guidelines for in vitro and in vivo genetic toxicology testing. Environ Mol Mutagen 35:206-221.

Vasconcelos T, Sarmento B and Costa P (2007) Solid dispersions as strategy to improve oral bioavailability of poor water soluble drugs. Drug Discov Today 12:1068-1075.

Wahlstrom B and Blennow G (1978) A study on the fate of curcumin in the rat. Acta Pharmacol Toxicol 43:86-92.

Wolfsegger MJ, Jaki T, Dietrich B, Kunzler JA and Barker K (2009) A note on statistical analysis of organ weights in non-clinical toxicological studies. Toxicol Appl Pharmacol 240:117-122.

Yallapu MM, Jaggi M and Chauhan SC (2012) Curcumin nanoformulations: A future nanomedicine for cancer. Drug Discov Today 17:71-80.

Yu WG, Xu G, Ren GJ, Xu X, Yuan HQ, Qi XL and Tian KL (2011) Preventive action of curcumin in experimental acute pancreatitis in mouse. Indian J Med Res 134:717-724.

Yuan JM, Li XD, Liu ZY, Hou GQ, Kang JH, Huang DY and Du SX (2011) Cisplatin induces apoptosis via upregulating Wrap53 in U-2OS osteosarcoma cells. Asian Pac J Cancer Prev 12:3465-3469.

Zhang JG, Viale M, Esposito M and Lindup WE (1999) Tiopronin protects against the nephrotoxicity of cisplatin in the rat. Hum Exp Toxicol 18:713-717.

Zhou H, Beevers CS and Huang S (2011) The targets of curcumin. Curr Drug Targets 12:332-347.

Associate Editor: Daisy Maria Fávero Salvadori

License information: This is an open-access article distributed under the terms of the Creative Commons Attribution License (type CC-BY), which permits unrestricted use, distribution and reproduction in any medium, provided the original article is properly cited. 